\title{
Study on Adjustment Method of Area Well under Four-point Method of Ultra High Water Period
}

\author{
Xiaoling $\mathrm{Ma}^{1, \mathrm{a}}$ \\ ${ }^{1}$ Daqing Oil Field Co., Ltd. Second Production Plant, Daqing, Heilongjiang, 163411 \\ ${ }^{\mathrm{a}}$ email
}

Keywords: Four-Point Method for Areal Well; Four-Point Method for Areal Well; Encryption Adjustment; Strata Well Reconstruction

\begin{abstract}
Oil Development has entered the special high water cut stage, experienced only once encryption adjustment, development process, exposing the well spacing density, low degree of recovery, the problem of higher water cut, the original four-point method area network has been well suited the current development status quo. Thus typical block selected to carry out encryption and strata Well Reconstruction adjustment mode research and exploration. Adoption of new wells and old wells utilization cloth, the four-point method for areal well transforming into a five-spot well pattern area on the portrait, according to the nature of refined oil mining segment level; on a plane, narrow injector spacing, perfect single sand body relationship between injection, injection and production increases towards improving the degree of use of oil, in order to further improve the development effect in transitional zone, provide a reliable basis. Art methods have formed guide and reference for similar cloth oil wells.
\end{abstract}

\section{Introduction}

Oilfield development practice shows that the multiple layers of sandstone oilfield, oilfield overall development principle is from coarse to fine development process. For domestic oil fields, the initial field development more heterogeneous reservoir, reservoir or general different strata using different well pattern, injector spacing, deploy sets of strata Well. When the high water cut oilfield and high water - the original development of integrated adjustment technology can not fully meet the oil field development and production needs, therefore, each for their own oilfield geological features, network specific characteristics of existing wells, made in the late high water cut and comprehensive utilization of high water cut stage, strata pattern adjustment, optimization and reorganization, development adjustment layer-based swaps, to further improve the single sand body or oil sands relationship between injection and fully tap the remaining oil, which guide field rational development, achieve sustainable development, is important [1-7].

\section{Reservoir Sedimentary Characteristics and Its Development Status}

Reservoir sedimentary characteristics. The field for large continental river basin shallow delta depositional system, reservoir and more serious heterogeneity, the interlayer, the plane and the inner layer of great contradictions [8]. Study area is located in the east wing of anticline, B water reservoir for the transitional area, A reservoir of pure oil. The area A, B reservoir characterized by deposition can be divided into three sub-phases, phase shunt plain inner delta front and delta outer front phase. Sedimentary sand body in the delta front facies and outer front are with a thin layer of sediments. Wherein the inner delta front facies total of 20 units, the average single well drilled sandstone thickness of $19.3 \mathrm{~m}$, the effective thickness of $8.0 \mathrm{~m}$, accounting for total drilled sandstone thickness and effective $38.0 \%$ and $46.2 \%$, respectively; relative to the leading edge of the outer thin layer deposition a total of 42 units, the average single well drilled sandstone thickness of $24.1 \mathrm{~m}$, the effective thickness of $5.9 \mathrm{~m}$, accounting for total drilled sandstone thickness and effective $47.4 \%$ and 34.1\%, respectively. P Various deposition plane micro coexist, river sand and sand body development of smaller, phase transition complex.

Development status. Well the study area based four-point method area Well well pattern, 
injector spacing 350m, once encrypted adjusted development for 27 years, at the midpoint of the original triangle mesh cloth well well, forming a line injection mode, injection and production well spacing 200m, the local point of view is still well four-point method area well pattern. The current development of the situation worsening, oil injection and production capacity deteriorates, finish with injection wells $42.8 \%$ Number of open wells, insufficient liquid supply is low and sinking wells accounted for $43.1 \%$ of the number of wells, the use of oil in the proportion of $80 \%$ comprehensive water has reached $95.34 \%$, recovery was $43.51 \%, 5.89 \%$ lower than the pure oil zone; linear injection and four-point method for areal well injection direction less than the five-spot well pattern, high water cut wells of adaptability deteriorated. For this reason, to carry out encryption and strata Well Reconstruction adjustment mode research, exploration wells adaptation research area network deployment.

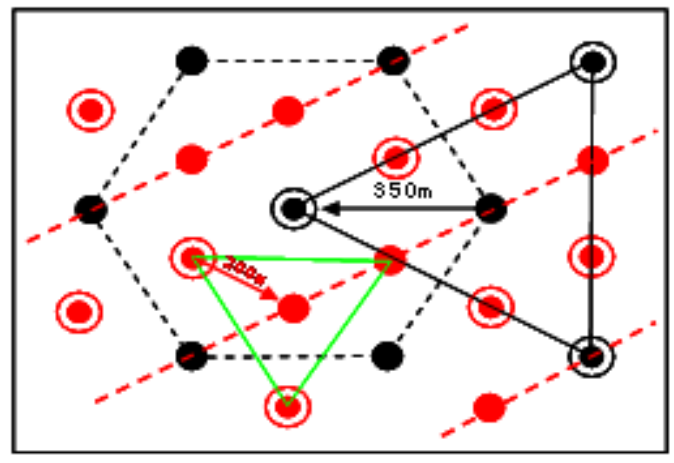

Fig.1 Aschematic diagram wells

\section{Single Body Injection - Production Relationship Evaluation}

Accurate and objective understanding of single sand body Injection-production status and is the key to perfect high water - to improve development effectiveness, and therefore the effective control theory, based on the results of fine geological study to single-well, single, single sand body as an Analysis consider oil wells perforation condition, injector spacing, type of sand, connectivity, efficiency orientation and other factors, combined static and dynamic evaluation of single sand body to improve the degree of relationship between injection [8-9].

Fine Geological studies show that the study area of river sand and a thick layer of sand body poor continuity, phase change frequently, the current injector spacing, the single sand body corresponding to the effective injection and production rate. Basic well to exploit thick oil-based, injection-production between the thick layer of sand body connectivity relations have four, river sand - river sand, river sand - the main sand body sand - river sand, the main - the main communication, this 4 species communicating relationship sandstone and communication accounted for $25.6 \%$ and the effective thickness of $42.2 \%$. Adjacent area $300 \mathrm{~m}, 300 \mathrm{~m}$ away from the injection and production wells, the proportion of communication between the thick layer of sand can reach 42.7\% and 58.1 percentage points.

Primary encryption adjust the midpoint triangle of cloth well in basic well formed, with the original composition on diagonal Well, a lack of appropriate encryption injection and production wells on the basis of the direction of the well, and are therefore, on the basis of thin poor oil well injection wells at the cloth mining imperfect. Statistics alone primary encryption well water flooding control extent, thickness ratio of $76.5 \%$ of total communication, which has been communicated thickness ratio of 53.9\%, the proportion of two-way communication with a thickness of $21.7 \%$, the proportion of multi-directional communication with a thickness of only $0.9 \%$. Basic well injection well connected through the layer due to the interference between layers, the thickness of this part of the communication status of water is not guaranteed.

Numerical simulation study shows that water flooding, flooding effect from good to bad order: five-spot well pattern, four-point method well network or seven law Well, linear Well, inverted nine spot well pattern. Study Area A, B reservoir four-point method for areal well into development, 
compared with the five-spot well pattern area in the dry recovery, the former than the latter, but during the aqueous extraction, in particular, to the high water content development phase, this advantage is gradually obvious. With respect to the five-spot area Well 4 injection and production direction, four-point method for areal well there are three injection and production direction, linear Well only 1 to 2 injection and production direction, after years of waterflooding, injection-production channel has high water flooded, sweep the area to shrink, later adjustment difficult.

\section{Potential of Remaining Oil}

Numerical simulation results show that: block recovery degree $36.0 \%, 54.6 \%$ water saturation. The thickness ratio of reservoir sandstones Statistics different water level thickness ratio of water less than $90 \%$ of $45.9 \%$, the effective thickness of $38.3 \%$; water reservoir sandstone thickness ratio of 90 to $96 \%$ was $22.7 \%$, effective thickness ratio of $23.4 \%$; moisture content greater than $96 \%$ of the reservoir sandstone thickness ratio was 31.4\%, effective thickness ratio of 38.4\%.

Table 1 Numerical simulation of different water level zone thickness ratio table

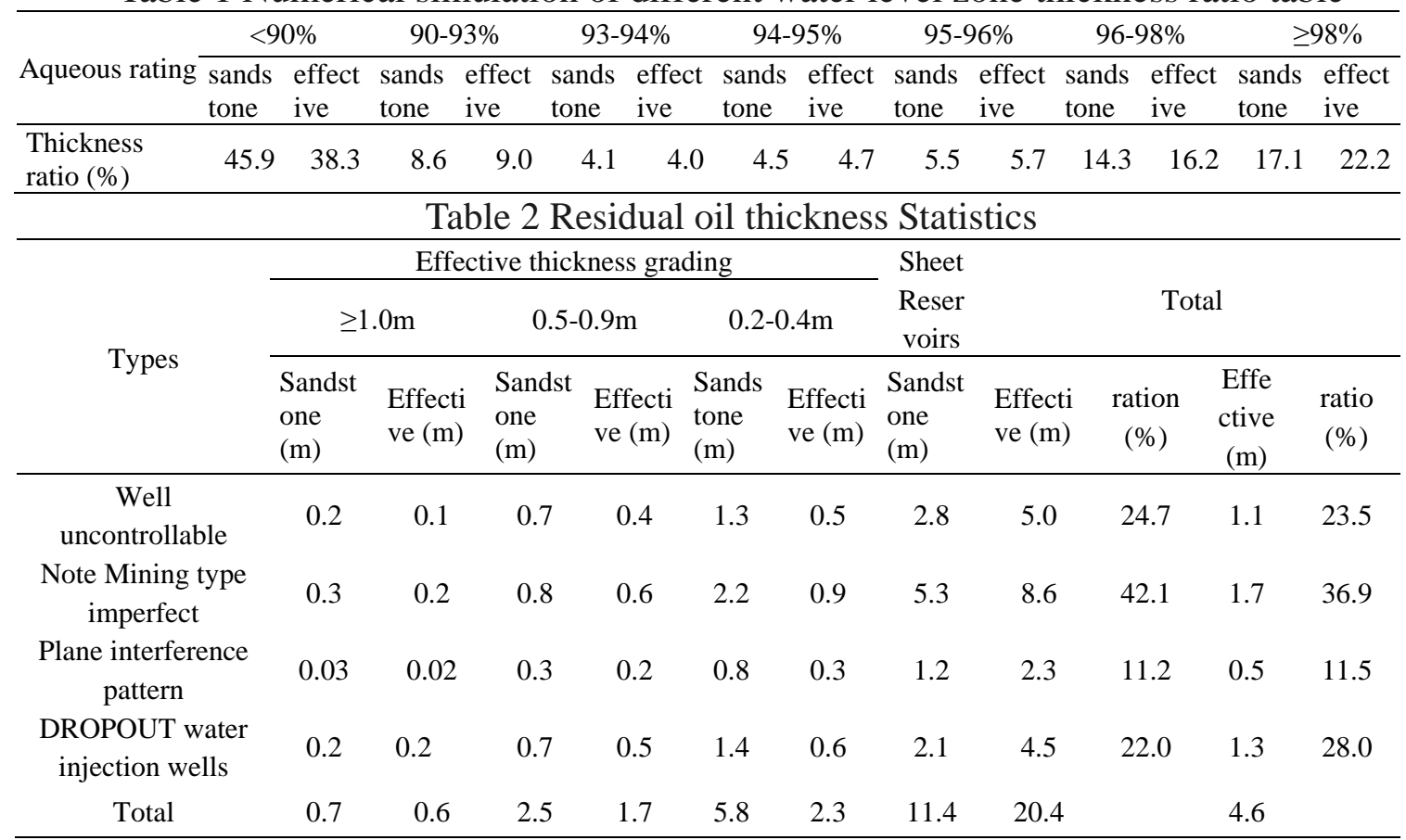

Comprehensive analysis of remaining oil sands 20.40 meters, 4.6 meters effectively, type a pound net uncontrollable and Injection imperfect main type, sandstone and effective rates were $66.8 \%$ and accounted for $60.4 \%$.

\section{Well Optimal Adjustment and Its Evolution}

Through comprehensive analysis, there are still plenty of remaining underground reserves of unspent, although the water cut close to the limit moisture content, but the use of reserves and flooding still exists a certain degree of imbalance. Since the inner flow units and the presence of heterogeneity, the plane appears to correspond well injection and production wells group, in fact, reserves have not been brought under control well network. Each oilfield development practice shows that by improving the relationship between injection wells gateway adjustment can greatly improve oil reserves producing degree; by major reservoirs Well thinning, non-encrypted major reservoirs Well REALIGUMENT, also achieved very good results. Thus, according to oil development wells and strata network status personalized design adjustment method [10-11].

Applications modulus values intended to establish a typical model to study in different permeability reservoir water flooding optimal well spacing. With the injection and production wells to increase spacing, recovery overall downward trend (Figure 2). 


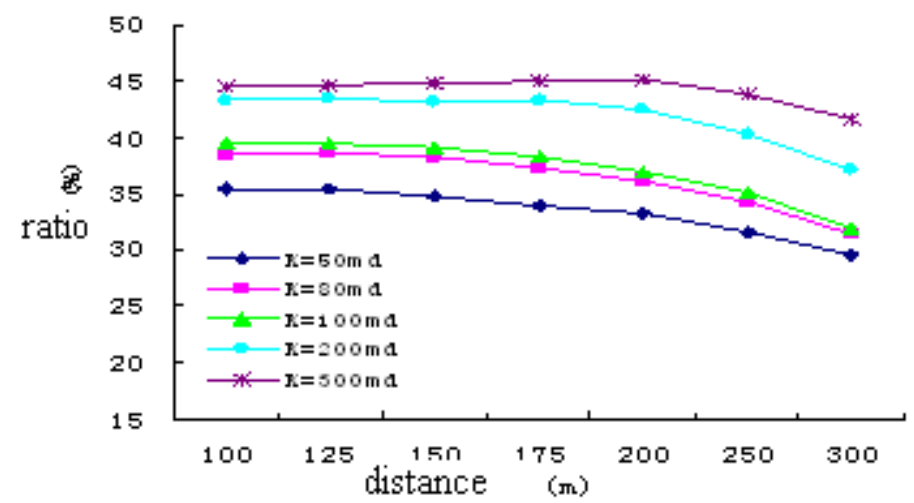

Fig. 2 Different Permeability Reservoir

Permeability of $100 \times 10-3 \mu \mathrm{m} 2$ of oil, corresponding to a reasonable injection - production well spacing should be less than 150 meters. Permeability of $300 \times 10-3 \mu \mathrm{m} 2$ of oil, corresponding to a reasonable injection - production well spacing should be about 200 meters.

According to reservoir development characteristics of the strata subdivided into high-permeability layer and a low permeability layer, layer-based design of two kinds of combinations, ie sandstone reservoir properties according to segments and segment. Comparison shows: Press sandstone segments, broken down between the upper longitudinal objects Note Mining clear relationship between the injection and production plane perfect relationship; single-layer card segment, plugging process is simple and beneficial to the late three oil production wells utilization.

Table 3 Subdivision objects combination regimen Comparison Table

\begin{tabular}{|c|c|c|c|c|c|c|c|}
\hline Combinations & Type & Subdivision objects & Layer & $\begin{array}{l}\text { Sandst } \\
\text { one } \\
\text { thickn } \\
\text { ess } \\
\text { (m) } \\
\end{array}$ & $\begin{array}{l}\text { the } \\
\text { effecti } \\
\text { ve } \\
\text { thickn } \\
\text { ess }\end{array}$ & $\begin{array}{l}\text { Permeabil } \\
\text { ity } \\
\left(10^{-3} \mu \mathrm{m}^{2}\right)\end{array}$ & $\begin{array}{c}\text { Interlayer } \\
\text { permeability } \\
\text { Differential }\end{array}$ \\
\hline \multirow{2}{*}{$\begin{array}{c}\text { Press } \\
\text { reservoir } \\
\text { properties }\end{array}$} & $\begin{array}{c}\text { High-permea } \\
\text { bility layer }\end{array}$ & $\begin{array}{c}\text { Effective thickness of the oil layer } \\
\qquad \geqslant 0.5 \mathrm{~m}\end{array}$ & 12.5 & 23.2 & 14.8 & 323.2 & 6.4 \\
\hline & $\begin{array}{c}\text { Low } \\
\text { permeability } \\
\text { layer }\end{array}$ & $\begin{array}{l}\text { Outer reservoir effective thickness } \\
<0.4 \mathrm{~m} \text { and Table }\end{array}$ & 44.8 & 30.1 & 4.0 & 41.5 & 2.7 \\
\hline \multirow{2}{*}{$\begin{array}{c}\text { Press } \\
\text { Sandstone }\end{array}$} & $\begin{array}{c}\text { High-permea } \\
\text { bility layer }\end{array}$ & $\begin{array}{l}\text { A II 7-12, and the following group } \\
\text { B }\end{array}$ & 26.0 & 26.8 & 10.8 & 270.6 & 6.4 \\
\hline & $\begin{array}{c}\text { Low } \\
\text { permeability } \\
\text { layer }\end{array}$ & Other Sandstone & 31.4 & 26.5 & 7.9 & 140.3 & 5.8 \\
\hline
\end{tabular}

Adopt a new way cloth well with the existing network utilization, the use of injection wells will be utilized as well rafts of injection wells, production wells in the row between the cloth well new injection wells, four water injection wells in the middle of new cloth production wells, breakthrough original four-point method well pattern, form a regular injection and production wells $135 \mathrm{~m}$ five-spot well pattern from the area of injection and production wells from the $200 \mathrm{~m}$ down to $135 \mathrm{~m}$, the exploitation of low permeability reservoirs (Fig. 3).

The remaining old wells formed NNW 350m well spacing, NEE 200m irregular nine spot well away from the area of a rectangle well pattern (Fig. 4), the exploitation of high permeability reservoir. The longitudinal direction and provenance in the same direction, keeping well away from the original 350m, well away from the source direction perpendicular reduced to $200 \mathrm{~m}$. 


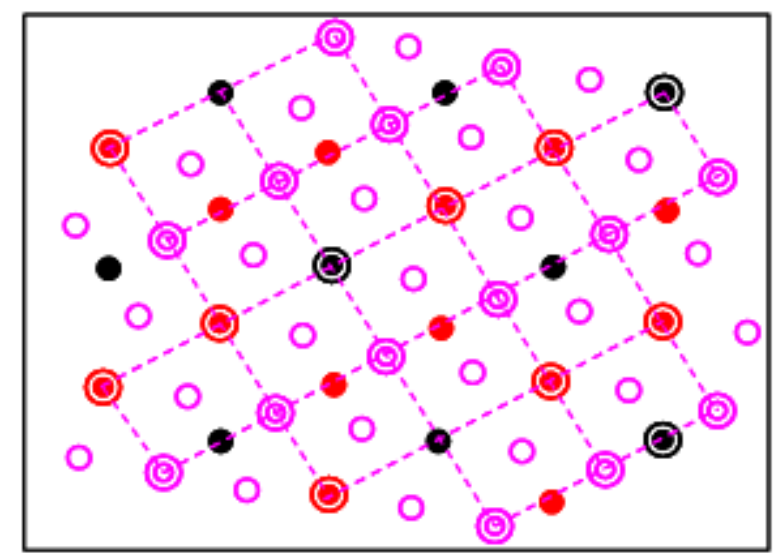

Fig.3 wells in low permeability reservoirs cloth schematic

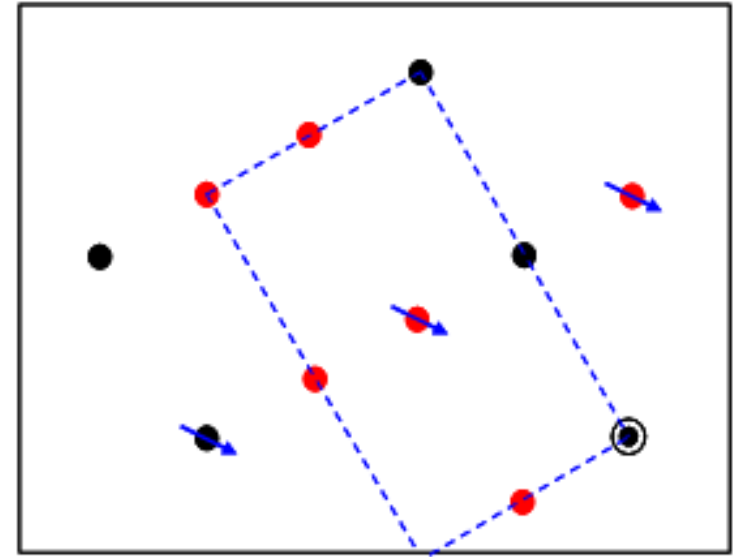

Fig. 4 high permeability reservoirs irregular nine spot well pattern area

After the adjustment, the new and old wells bit relations coordination, increase water direction, flow direction changes, and more to increase the degree of water flooding control 37.4 percent. The implementation of the adjustment method in the study area, the new production well drilling, oil production 2.2t, 92.5\% water cut, the numerical simulation, the block can be adjusted EOR 3.38\%.

\section{Well Late Evolution}

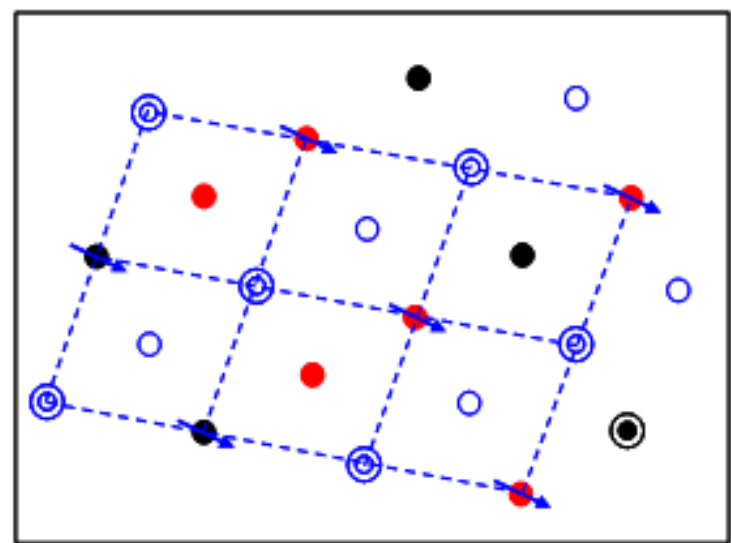

Fig.5 Evolution area well away from the nine point 200m five-spot well pattern area 


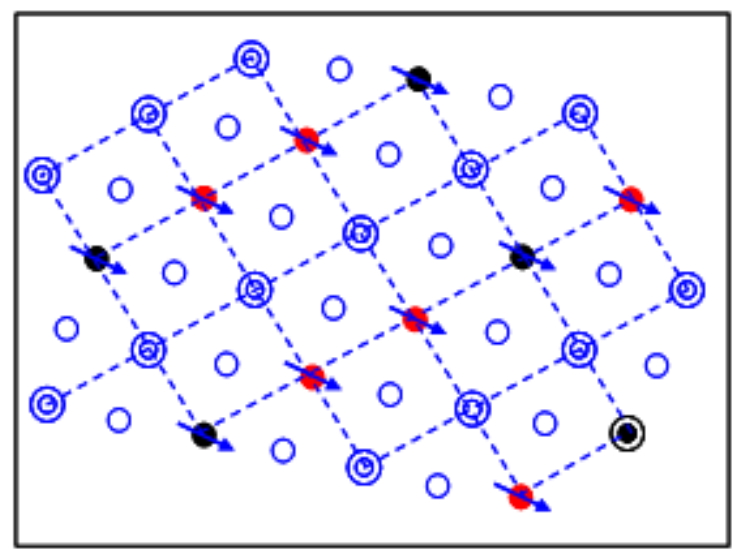

Fig.6 200m well spacing well spacing evolution 135m five-spot well pattern area Late evolution Well, considering the development of EOR two strata, irregular nine spot well pattern of injection wells can be online between rows of new cloth between the injection and production wells, production wells will be utilized as well row between between injection and production wells using wells and new wells formed cloth injector spacing 200m of five-spot well pattern area (Fig. 5). The web may well evolve further, all the wells utilized as injection wells, four wells center of the new fabric production wells, injection and production wells are formed $135 \mathrm{~m}$ five-spot well pattern area (Fig. 6) pitch. Two 135m five-spot well pattern area available for EOR, water flooding and mutually strata left exit.

\section{Conclusions and Awareness}

The size of the study area has a surplus reserves, potential adjustments with encryption, provide the material basis for the production of water flooding on the scale.

After pressing the sandstone strata subdivision, the contradictions between the upper longitudinal reduced interlayer clear injection and production relations; improve the relationship between injection on a plane, in favor of the use of the reservoir.

New, old wells utilization encrypt adjustment, breaking the original four-point method area well pattern, adjusted for the five-spot well pattern area, increasing the water direction, flow direction changes, and more to increase the degree of control of water flooding.

Well rule the adjustment is formed, it is possible to effectively improve ultimate oil recovery waterflood and EOR development for the latter to leave room for adjustment.

\section{References}

[1] Xinjiang Petroleum Geology Edit Translations of School Large Multi-Line Oilfield Development Principles of Rational Development [J]. Xinjiang Petroleum Geology, 1999, (05): $339-452$.

[2] Sun Guo. High Water-Well Recombinant Technology To Optimize Sun States Shengtuo Oilfield [J]. Geology and Recovery, 2005 (03): 48-51.

[3] Zhao Zhifeng. Fluvial Sandstone Reservoirs With High Water - Pattern Adjustment Technology Research [D]. China University of Petroleum, 2007.

[4] Li Yuanping, Du Jinhong. Mao Xiuling. Translation Theory and Practice of Multi-Field Development [J]. Tuha Oil, 2003, (04): 391 - 394.

[5] Wang Yanjie, Zhang Hongmei. Other Multi-Layer System-Based Oilfield Development Division and Well Spacing [J]. Petroleum Geology, 2002, (01): 40 To 43.

[6] Wang Sanjian, Liu Guoqi. Applications Well Comprehensive Adjustment Technique in The High Water Cut Of Development [J]. Jianghan Petroleum Institute Reported That In 2003, (04): 94 -95 . 
[7] Wang Yanjie, Zhang Hongmei, Jiang Xiaohui. Multi-Layer System-Based Oilfield Development Division And Well Spacing [J]. Petroleum Geology, 2002, (01): 40-45.

[8] Xu Zhengshun. Lasaxing Oilfields With High Water - Adjustment Techniques [J]. Petroleum Geology And Development, 2009,28 (5): 76-82.

[9] Qi Chunyan. Sandstone Oilfield Single Sand Body Note Evaluation And Adjustment Mechanisms On Mining. Daqing Oilfield Co., Ltd. .2006

[10] Zhang Shiming. Research Helping Late High Water Cut Wells Rearrangement Policy Limits [J]. Special Reservoir, 2005, (02): 35 To 39.

[11] Chen Minfeng, Jiang Hanqiao, Zeng Yuxiang. Had Developed Serious Heterogeneous Reservoirs Permeability Ratio Boundary Layer Recombination [J]. China Offshore Oil And Gas, 2007, (05): 319 - 326. 